\title{
Trunk fat and leg fat in relation to free triiodothyronine in euthyroid postmenopausal women
}

\author{
Xiaomin Nie*, Yiting Xu*, Xiaojing Ma, Yun Shen, Yufei Wang and Yuqian Bao
}

Department of Endocrinology and Metabolism, Shanghai Jiao Tong University Affiliated Sixth People's Hospital; Shanghai Clinical Center for Diabetes; Shanghai Key Clinical Center for Metabolic Disease; Shanghai Diabetes Institute; Shanghai Key Laboratory of Diabetes Mellitus, Shanghai, China

Correspondence should be addressed to X Ma or Y Bao: maxiaojing@sjtu.edu.cn or yqbao@sjtu.edu.cn

*(X Nie and $Y \mathrm{Xu}$ contributed equally to this work)

\section{Abstract}

Background: A high level of free triiodothyronine (FT3) within the reference range may be a potential metabolic risk marker. However, the relationship between different fat depots and FT3 has remained unclear.

Objective: We aimed to explore the relationships between segmental fat distribution and FT3 in euthyroid middle-aged and elderly men and postmenopausal women.

Methods: A total of 891 subjects (394 men and 497 women) were enrolled. A bioelectrical

Key Words
- trunk fat
- leg fat
trunk fat mass to leg fat
mass ratio
- free triiodothyronine
impedance analyzer was used to measure total, trunk, arm and leg fat mass (FM) and fat percentage (fat\%). The leg fat mass to trunk fat mass ratio (LTR) was calculated to evaluate the relative distribution of leg fat compared with that of trunk fat. Thyroid hormones were measured by electrochemical luminescence immunoassay.

Results: FT3 in men did not change significantly with increases in LTR quartiles, while FT3 in women decreased significantly ( $P$ for trend $=0.004$ ). In multivariate linear regression analysis, multiple metabolic and cardiovascular risk factors were adjusted. The LTR was negatively related to FT3 in women $(P<0.05)$. After further mutual adjustment for trunk fat and leg fat parameters, trunk FM and fat\% were positively related to FT3, while leg FM and fat\% were negatively related to FT3 in women (all $P<0.05$ ).

Conclusions: In euthyroid postmenopausal women, trunk fat was positively correlated with FT3, whereas leg fat was negatively correlated with FT3. Our findings supported that a high level of FT3 within the reference range was related to adverse fat distribution.

\section{Introduction}

Obesity is the key pathogenic factor of type 2 diabetes and cardiovascular disease (1). The disease risk associated with obesity is related not only to fat content but also to fat distribution. Abdominal obesity characterized by an 'apple-shape' significantly increases the risk of type 2 diabetes and cardiovascular disease (2). In contrast to that, a 'pear-shape' with most fat accumulating in the lower body is found to have metabolic and cardiovascular protective effects (3).
Free triiodothyronine (FT3) is the bioactive form of thyroxines. FT3 regulates basal metabolic rate, promotes fat decomposition and acts on the cardiovascular system through adrenergic signaling (4). Previous studies have found that a high level of FT3 within the reference range was positively related to BMI and waist circumference $(5,6)$. Non-alcoholic fatty liver disease (NAFLD) is one of the most common complications of obesity. In recent years, some studies found that a high level of FT3 within

This work is licensed under a Creative Commons Attribution-NonCommercial-NoDerivatives 4.0 Internationab bicense ifica.com at 04/26/2023 08:16:54AM 
the reference range was related to the risk of NAFLD and multiple adverse metabolic and cardiovascular risk factors $(5,7,8)$, which suggests that a high level of FT3 within the reference range may be a potential adverse metabolic risk marker. The middle-aged and elderly population is at high risk of metabolic and cardiovascular disease; thus, it is meaningful to explore the associations between different fat depots and FT3 in this age group.

BMI and waist circumference are simple indexes to evaluate obesity, but cannot be used to reflect the distribution of different fat depots. Segmental fat depots (trunk, arm and leg) measured by segmental bioelectrical impedance analysis (sBIA) are highly consistent with those measured by dual energy X-ray absorptiometry (9). sBIA can accurately evaluate body fat content with simple operation and lightweight size. None of the previous studies have focused on associations between segmental fat distribution and FT3. In the present study, we aimed to explore the relationship between segmental fat distribution and FT3 in euthyroid middle-aged and elderly men and postmenopausal women. Trunk fat and leg fat were found to have an inverse relationship with metabolic and cardiovascular disease in previous studies $(3,10,11)$. The relationship between arm fat and cardiovascular metabolic risk was nonsignificant or weak $(12,13)$. Thus, we calculated the leg FM to trunk FM ratio (LTR) to study the relationship between a tendency of fat to accumulate in the legs rather than trunk and FT3.

\section{Materials and methods}

\section{Study population}

Men and postmenopausal women aged 50 years or older were recruited from Shanghai communities from October 2015 to July 2016. Postmenopausal status was defined as at least 1 year of amenorrhea in the absence of other medical conditions (14). The methods of population recruitment and data collection were described in our previous study (15). All participants provided informed consent and received questionnaires, a physical examination, laboratory tests and segmental fat measurements. The exclusion criteria included a history of thyroid disease with thyroxine supplement or anti-thyroid therapy; abnormal thyroid function; a history of diabetes or cardiovascular disease; moderate-to-severe anemia; malignancy or an intracranial mass lesion; severe kidney or liver dysfunction; acute infection; hypoalbuminemia; taking lipid-lowering drugs, hypotensive drugs, weight-loss pills, glucocorticoids, sex hormones, amiodarone or lithium. The study was approved by the Ethics Committee of the Shanghai Jiao Tong University Affiliated Sixth People's Hospital and was carried out following the guidelines of the 1964 Declaration of Helsinki.

\section{Anthropometric and biochemical assessments}

Height, body weight and blood pressure were measured according to standard methods, which were described in our previous study (15). BMI was equal to the body weight $(\mathrm{kg})$ divided by the height squared $\left(\mathrm{m}^{2}\right)$. Systolic blood pressure (SBP) and diastolic blood pressure (DBP) were determined by the mean blood pressure from three measurements taken at 3-min intervals.

All subjects underwent a 75-g oral glucose tolerance test in the morning after an overnight fast of $10 \mathrm{~h}$. The measurements of fasting plasma glucose (FPG), 2-h plasma glucose ( $2 \mathrm{~h} \mathrm{PG})$, glycated hemoglobin A1c (HbA1c), fasting insulin (FINS), triglyceride (TG), total cholesterol (TC), high-density lipoprotein cholesterol (HDL-c), and low-density lipoprotein cholesterol (LDL-c) were performed according to methods described in our previous study (15). Estradiol (E2) was detected by chemiluminescent microparticle immunoassays on an Architect i2000SR analyzer (Abbott GmbH \& Co. KG). The level of insulin resistance was evaluated by the homeostasis model assessment of insulin resistance (HOMA-IR) with the following formula: HOMA-IR=FINS $(\mathrm{mU} / \mathrm{L}) \times \mathrm{FPG}(\mathrm{mmol} / \mathrm{L}) / 22.5(16)$.

A Cobas e601 analyzer (Roche Diagnostics $\mathrm{GmbH}$ ) was used to measure FT3, free thyroxine (FT4) and thyroid-stimulating hormone (TSH). The reference range and intra- and interassay coefficients for FT3 were $3.10-6.80 \mathrm{pmol} / \mathrm{L}, \quad<7.0$ and $<8.0 \%$, respectively; for FT4, they were $12.00-22.00 \mathrm{pmol} / \mathrm{L},<5.0$ and $<7.0 \%$, respectively; and for TSH, they were $0.27-4.20 \mathrm{mIU} / \mathrm{L}$, $<3.0$ and $<8.0 \%$, respectively.

\section{Measurement of segmental fat distribution}

An automatic bioelectrical impedance analyzer (TBF-418B; Tanita Corp., Tokyo, Japan) was used to measure total, trunk, arm and leg fat mass (FM) and fat percentage (fat\%) according to a previously described method (15). To evaluate the tendency of fat accumulation in the legs rather than the trunk, the LTR was calculated as leg FM (kg) divided by trunk FM (kg). 


\section{Statistical analysis}

The normality of the distribution of variables was evaluated by the Kolmogorov-Smirnov test. Normally distributed variables are expressed as the mean \pm standard deviation. Variables with a skewed distribution are expressed as the median (interquartile range). For normally distributed variables, one-way ANOVA was used for trend analysis. For skewed variables, the Kruskal-Wallis $H$-test was used for trend analysis. Partial correlation analysis was used to explore the age- and BMI-adjusted relationships between fat parameters and thyroid hormones. Multivariate linear regression analysis was used to explore the relationship between segmental fat parameters and thyroid hormones. Considering close correlations among segmental fat parameters, multicollinearity was analyzed for each linear regression model. A variance inflation factor $>10$ indicated serious multicollinearity. SPSS version 22.0 (SPSS, Inc.) statistical software was used for all data analyses. A twotailed $P$ value $<0.05$ was considered statistically significant.

\section{Results}

\section{Clinical characteristics of the study participants}

The study included 891 subjects with an age range of 50-81 years (mean age 61 \pm 5 years). There were 394 men and 497 postmenopausal women. The medians of BMI, total FM and total fat\% were $23.0(21.2-25.1) \mathrm{kg} / \mathrm{m}^{2}$, $16.0(12.2-20.1) \mathrm{kg}$, and 25.9 (20.0-32.3)\%, respectively. The medians of FT3, FT4 and TSH were 4.93 (4.60-5.29) $\mathrm{pmol} / \mathrm{L}, 16.55$ (15.31-17.71) pmol/L and 2.17 (1.55-2.87) $\mathrm{mIU} / \mathrm{L}$, respectively.

Both men and women were divided into four groups according to LTR quartiles: Q1<0.58, Q2 0.58-0.63, Q3 0.64-0.73 and Q4>0.73 for men; and Q1<0.64, Q2 0.64-0.70, Q3 0.71-0.80 and Q4>0.80 for women (Table 1). In men, age, BMI, total FM, total fat\%, DBP, FPG, FINS, HOMA-IR and E2 decreased significantly with increasing LTR quartiles (all $P$ for trend<0.05). In women, BMI, total FM, total fat $\%$, SBP, FPG, HbA1c, FINS, HOMA-IR, TG and E2 decreased significantly with increasing LTR quartiles (all $P$ for trend $<0.05$ ). In both genders, HDL-c significantly increased with increasing LTR quartiles (all $P$ for trend $<0.05$ ).

\section{Changes of thyroid hormones in LTR quartiles}

In men, FT3, FT4 and TSH did not significantly change with increasing LTR quartiles (all $P>0.05$ ). In women, only FT3 significantly decreased with increasing LTR quartiles. The medians of FT3 from the Q1 to the Q4 group of LTR quartiles were $4.84(4.56-5.19) \mathrm{pmol} / \mathrm{L}$, 4.78 (4.48-5.15) pmol/L, 4.74 (4.52-5.03) pmol/L and $4.64(4.34-4.93) \mathrm{pmol} / \mathrm{L}(P$ for trend=0.004). In women, FT4 and TSH did not change significantly with increasing LTR quartiles (all $P>0.05$, Fig. 1).

\section{Partial correlation analysis of segmental fat parameters and thyroid hormones}

In men and women, trunk FM was 7.5 (5.5-9.9) $\mathrm{kg}$ and 9.9 (7.4-12.1) $\mathrm{kg}$, trunk fat\% was $21.0(16.5-25.3) \%$ and $30.9(25.8-35.1) \%$, arm FM was $1.0(0.8-1.2) \mathrm{kg}$ and $1.4(1.2-1.9) \quad \mathrm{kg}$, arm fat\% was $1.5 \quad(1.3-1.7) \%$ and $2.6(2.1-3.1) \%$, leg FM was $4.8(3.8-5.9) \mathrm{kg}$ and $6.8(5.8-8.0) \mathrm{kg}$, leg fat $\%$ was $7.0(6.1-8.0) \%$ and $11.9(11.1-12.8) \%$, and the LTR was $0.63(0.58-0.73)$ and $0.70(0.64-0.80)$, respectively.

Age and BMI were adjusted in the partial correlation analysis. In men, none of the fat parameters were related to FT3 (all $P>0.05)$. In women, total FM $(r=0.098, P=0.030)$, total fat $\% \quad(r=0.138, P=0.002)$, trunk FM $(r=0.124$, $P=0.006)$ and trunk fat $\% \quad(r=0.132, P=0.003)$ were positively related to FT3, while the LTR was negatively related to FT3 $(r=-0.147, P=0.001)$ (Fig. 2). In women, leg FM, leg fat\%, arm FM and arm fat\% were not related to FT3 (all $P>0.05$ ). None of the segmental fat parameters were related to FT4 or TSH in both men and women (all $P>0.05)$.

\section{Multivariate linear regression analysis for thyroid hormones}

Multivariate linear regression analysis was used to explore the relationships between segmental fat parameters and thyroid hormones in women (Table 2). In model 1, age, HOMA-IR, DBP, LDL-c and E2 were adjusted. Only LTR was negatively related to FT3 (standardized $\beta=-0.116, P<0.05)$, while total fat and other segmental fat parameters were not related to FT3 (all $P>0.05$ ). None of the segmental fat parameters were related to FT4 or TSH (all $P>0.05$ ).

Considering a significant and negative relationship between LTR and FT3, trunk fat and leg fat might be confounding factors of one another. Thus, we further created model 2 . In model 2 , all confounding factors involved in model 1 were included. In addition, leg FM and trunk FM were mutually adjusted, and leg fat $\%$ and trunk fat\% were mutually adjusted. Trunk FM and trunk

This work is licensed under a Creative Commons Attribution-NonCommercial-NoDerivatives 4.0 Internationab kicense.ifica, com at 04/26/2023 08:16:54AM 
Table 1 Clinical characteristics of subjects.

\begin{tabular}{|c|c|c|c|c|c|}
\hline \multirow[b]{2}{*}{ Parameters } & \multicolumn{4}{|c|}{ LTR quartiles } & \multirow[b]{2}{*}{$P$ for trend } \\
\hline & Q1 & Q2 & Q3 & Q4 & \\
\hline \multicolumn{6}{|l|}{ Men } \\
\hline$n$ & 98 & 99 & 99 & 98 & - \\
\hline Age (years) & $63(58-67)$ & $62(57-66)$ & $61(56-65)$ & $59(56-65)$ & 0.026 \\
\hline $\mathrm{BMI}\left(\mathrm{kg} / \mathrm{m}^{2}\right)$ & $23.9(22.4-25.5)$ & $24.4(22.2-26.3)$ & $23.5(22.2-25.0)$ & $22.0(19.5-23.4)$ & $<0.001$ \\
\hline Total FM (kg) & 16.0 (12.9-18.7) & $15.4(12.6-18.8)$ & $13.0(11.0-15.3)$ & $8.7(6.3-11.4)$ & $<0.001$ \\
\hline Total fat $\%$ & $23.1(20.0-25.3)$ & $21.8(19.5-24.0)$ & 18.7 (17.0-20.9) & 13.9 (10.9-16.4) & $<0.001$ \\
\hline SBP (mmHg) & 135 (122-148) & 134 (122-145) & 132 (123-144) & 130 (119-141) & 0.301 \\
\hline $\mathrm{DBP}(\mathrm{mmHg})$ & $80(74-88)$ & $81(74-87)$ & $80(74-86)$ & $77(71-82)$ & 0.020 \\
\hline FPG (mmol/L) & $5.7(5.4-6.2)$ & $5.7(5.4-6.0)$ & $5.8(5.5-6.3)$ & $5.6(5.3-6.1)$ & 0.044 \\
\hline 2 h PG (mmol/L) & $7.5(5.8-9.7)$ & $7.4(5.9-8.8)$ & $7.2(5.8-8.3)$ & $7.1(5.7-8.7)$ & 0.548 \\
\hline HbA1c (\%) & $5.7(5.4-6.0)$ & $5.6(5.4-5.9)$ & $5.6(5.4-5.9)$ & $5.6(5.4-5.8)$ & 0.614 \\
\hline FINS (mU/L) & $8.8(6.3-11.7)$ & $7.6(5.8-11.5)$ & $8.3(5.5-12.0)$ & $6.5(4.7-9.1)$ & 0.001 \\
\hline HOMA-IR & $2.2(1.5-3.5)$ & $2.0(1.4-3.1)$ & $2.1(1.4-3.4)$ & $1.6(1.1-2.4)$ & 0.001 \\
\hline $\mathrm{TC}(\mathrm{mmol} / \mathrm{L})$ & $5.3 \pm 0.9$ & $5.1 \pm 0.9$ & $5.2 \pm 0.9$ & $5.0 \pm 0.8$ & 0.102 \\
\hline $\mathrm{TG}(\mathrm{mmol} / \mathrm{L})$ & $1.6(1.2-2.3)$ & $1.4(1.0-2.3)$ & $1.5(1.0-2.2)$ & $1.2(0.9-2.0)$ & 0.105 \\
\hline HDL-c (mmol/L) & $1.3(1.1-1.5)$ & $1.2(1.1-1.4)$ & $1.3(1.1-1.4)$ & $1.4(1.1-1.6)$ & 0.018 \\
\hline LDL-c (mmol/L) & $3.3 \pm 0.7$ & $3.2 \pm 0.8$ & $3.2 \pm 0.7$ & $3.0 \pm 0.7$ & 0.051 \\
\hline E2 (pmol/L) & $99.1(80.8-125.7)$ & $113.8(91.8-128.5)$ & $95.5(84.4-110.1)$ & $99.1(80.8-121.2)$ & 0.009 \\
\hline \multicolumn{6}{|l|}{ Women } \\
\hline$n$ & 124 & 126 & 123 & 124 & - \\
\hline Age (years) & $60(57-63)$ & $61(56-65)$ & $61(57-64)$ & $60(57-63)$ & 0.355 \\
\hline $\mathrm{BMI}\left(\mathrm{kg} / \mathrm{m}^{2}\right)$ & $25.0(23.1-27.0)$ & $23.4(22.0-25.1)$ & $22.5(21.0-24.4)$ & $20.2(18.7-21.5)$ & $<0.001$ \\
\hline Total FM (kg) & $23.0(20.0-27.0)$ & $19.6(17.5-22.9)$ & $17.0(14.9-20.0)$ & $12.4(10.7-14.5)$ & $<0.001$ \\
\hline Total fat $\%$ & $36.5(34.1-39.0)$ & $32.7(30.9-35.5)$ & $30.4(28.3-33.4)$ & $24.8(22.1-26.7)$ & $<0.001$ \\
\hline $\mathrm{SBP}(\mathrm{mmHg})$ & $127(115-140)$ & 128 (118-140) & 125 (116-137) & $121(110-132)$ & 0.002 \\
\hline DBP (mmHg) & $76(71-83)$ & $76(70-81)$ & $74(68-82)$ & $73(68-80)$ & 0.080 \\
\hline FPG (mmol/L) & $5.8(5.5-6.2)$ & $5.7(5.4-6.2)$ & $5.7(5.4-6.0)$ & $5.5(5.1-6.0)$ & $<0.001$ \\
\hline 2hPG (mmol/L) & $7.1(6.1-9.2)$ & $7.1(5.6-9.0)$ & $7.2(6.1-8.5)$ & $6.8(5.6-8.1)$ & 0.274 \\
\hline HbA1c (\%) & $5.7(5.5-6.1)$ & $5.8(5.6-6.0)$ & $5.7(5.5-6.0)$ & $5.6(5.4-5.9)$ & 0.049 \\
\hline FINS (mU/L) & $11.3(8.5-14.3)$ & $10.2(7.3-14.1)$ & $8.3(6.8-10.5)$ & $6.3(4.8-7.7)$ & $<0.001$ \\
\hline HOMA-IR & $2.8(2.2-3.9)$ & $2.6(1.8-3.8)$ & $2.1(1.7-2.7)$ & $1.6(1.2-2.0)$ & $<0.001$ \\
\hline TC (mmol/L) & $5.7 \pm 0.9$ & $5.9 \pm 1.0$ & $5.6 \pm 0.9$ & $5.8 \pm 1.0$ & 0.974 \\
\hline TG (mmol/L) & $1.4(1.0-1.9)$ & $1.4(1.0-2.0)$ & $1.3(0.9-1.7)$ & $1.0(0.8-1.4)$ & $<0.001$ \\
\hline HDL-c (mmol/L) & $1.4(1.2-1.7)$ & $1.4(1.3-1.7)$ & $1.6(1.3-1.7)$ & $1.8(1.5-2.0)$ & $<0.001$ \\
\hline LDL-c (mmol/L) & $3.6 \pm 0.8$ & $3.6 \pm 0.9$ & $3.4 \pm 0.8$ & $3.4 \pm 0.9$ & 0.073 \\
\hline E2 (pmol/L) & 36.7 (18.4-47.7) & 38.5 (18.4-47.7) & $18.4(18.4-44.1)$ & $18.4(18.4-40.4)$ & 0.002 \\
\hline
\end{tabular}

Data were means \pm standard deviation or medians (interquartile range). Q1 < 0.58, Q2 0.58-0.63, Q3 0.64-0.73 and Q4 >0.73 for men; Q1 < 0.64, Q2 0.64-0.70, Q3 0.71-0.80 and Q4 > 0.80 for women.

2 h PG, 2-h plasma glucose; BMI, body mass index; DBP, diastolic blood pressure; fat\%, fat percentage; E2, estradiol; FINS, fasting insulin; FM, fat mass; FPG, fasting plasma glucose; HbA1c, glycated hemoglobin A1c; HDL-c, high-density lipoprotein cholesterol; HOMA-IR, homeostasis model assessmentinsulin resistance; LDL-C, low-density lipoprotein cholesterol; LTR, leg fat mass to trunk fat mass ratio; SBP, systolic blood pressure; TC, total cholesterol; TG, triglyceride.

fat $\%$ were both positively related to FT3 (standardized $\beta=0.303$ and 0.218 , respectively, all $P<0.05$ ). Leg FM and leg fat $\%$ were both negatively related to FT3 (standardized $\beta=-0.285$ and -0.195 , respectively, all $P<0.05$ ).

\section{Discussion}

In the present study, we found that trunk fat accumulation was related to increased FT3 in euthyroid postmenopausal women, while increased leg fat accumulation was related to decreased FT3. These relationships were independent of multiple metabolic and cardiovascular risk factors. In men, none of the fat parameters were related to thyroid hormones.

Obesity is closely related to FT3. Previous studies have found that BMI and waist circumference were positively related to FT3 in the euthyroid population $(5,6)$. A Mendelian randomization study indicated that higher BMI or FM played a causal role in increasing FT3 levels (17). Simple obesity indexes, such as BMI have been widely used in these studies. There have been few studies of associations between precisely-measured fat distribution and FT3. Lambrinoudaki et al. measured abdominal subcutaneous 

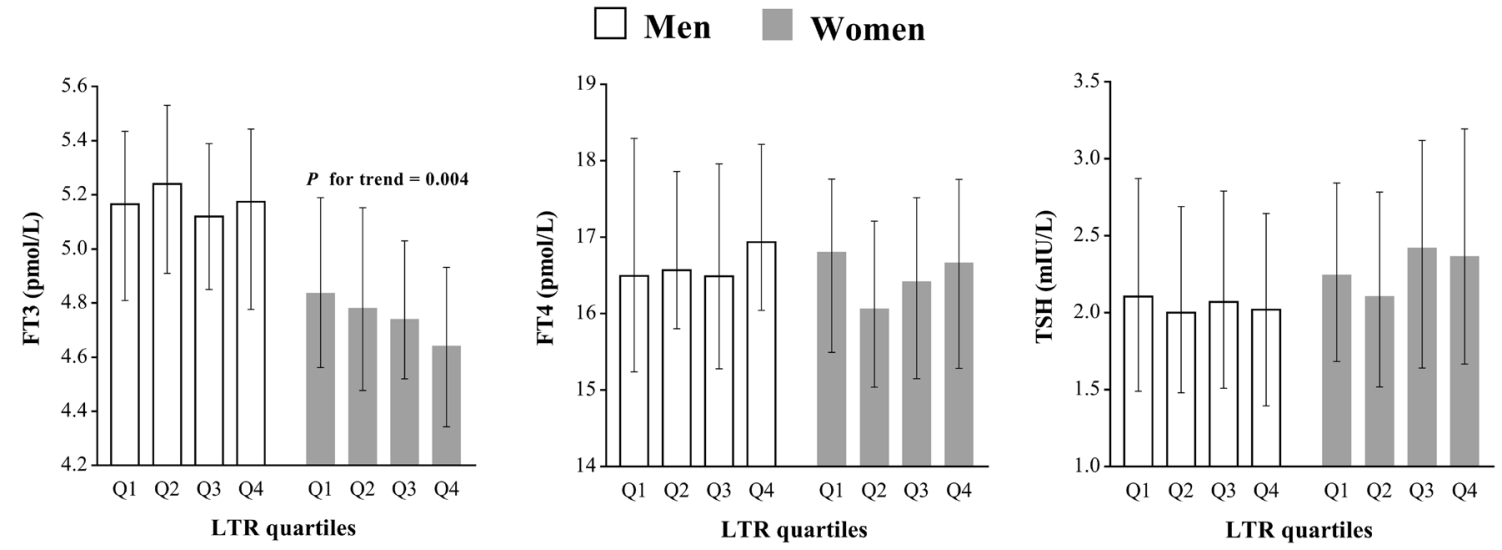

Figure 1

Thyroid hormones with LTR quartiles. FT3 decreased significantly as LTR quartiles increased in women $(P$ for trend $=0.004)$, but this trend was not significant in men. FT4 and TSH were not significantly changed as LTR quartiles increased in both men and women.

fat and preperitoneal fat through ultrasonography in 194 euthyroid postmenopausal women. They found that FT3 was positively associated with subcutaneous fat and preperitoneal fat (18). sBIA directly measures the bioelectrical impedance of the trunk, arms and legs. Subsequently, FM and fat $\%$ of different fat depots can be calculated based on the bioelectrical impedance. The segmental fat distribution measured by sBIA was highly consistent with that measured by dual energy X-ray absorptiometry $(r \geq 0.95, P<0.001)$ (9). Our findings in trunk fat were in consistent with Lambrinoudaki`s results. However, we further found a significant and negative relationship between FT3 and leg fat, while arm fat was not related to thyroid hormones. Moreover, our study found that there were no relationships between segmental fat distribution and thyroid hormones in men.

In this study, the LTR was calculated to reflect a tendency of fat accumulating in the legs rather than the trunk. In one previous study, Gavi et al. also calculated the limb fat to trunk fat ratio. Limb fat specifically referred to leg fat in their study. They found that the limb fat to trunk fat ratio was negatively related to insulin resistance and TG and positively related to HDL-c in a middle-aged and elderly population (19). The middle-aged and elderly population, especially postmenopausal women, is at high risk of metabolic and cardiovascular diseases (20). In our study, we also chose this high-risk population as study subjects. We found that the LTR was negatively related to FT3 in postmenopausal women. The correlation coefficient of total FM related to FT3 was weaker than that of trunk FM related to FT3 in the partial correlation analysis, and a negative relationship was found between the LTR and FT3. Thus, we conjectured that leg fat and trunk fat might be confounding factors of one another. In the multivariate linear regression analysis, trunk fat and leg fat parameters were mutually adjusted. We found that trunk fat parameters were positively related to FT3 and that leg fat parameters were negatively related to FT3. The result suggested that leg fat might alleviate the adverse effect between trunk fat and increased FT3. A sex difference existed in the relationship between segmental fat distribution and FT3 in our study, which might because women had a greater propensity to store fat in the lower body driven by the effects of sex hormones $(21,22,23)$.
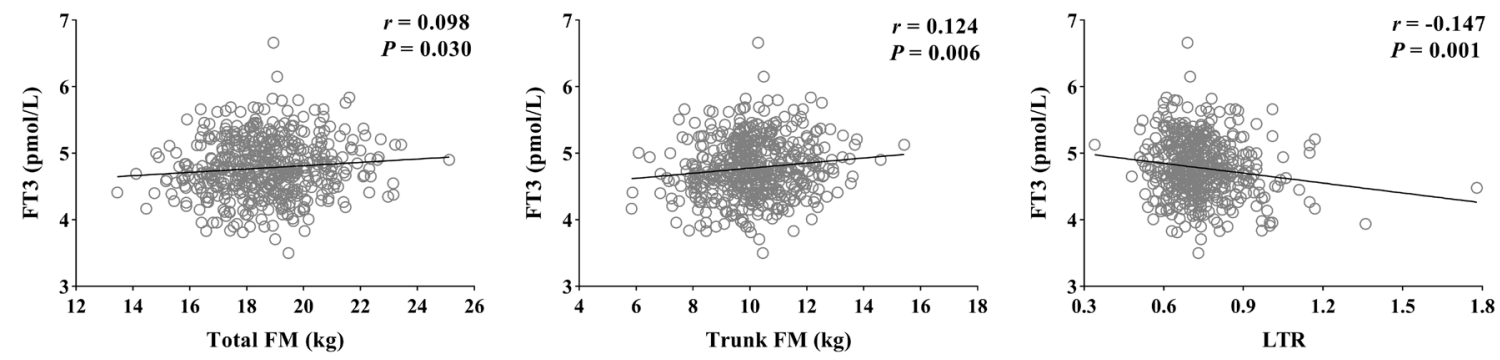

Figure 2

Partial correlation analysis of total FM, trunk FM, LTR and FT3 in women. Age and BMI were adjusted.

https://ec.bioscientifica.com https://doi.org/10.1530/EC-19-0394 (c) 2019 The authors Published by Bioscientifica Ltd

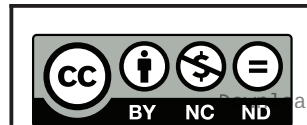

This work is licensed under a Creative Commons Attribution-NonCommercial-NoDerivatives 4.0 delnternationab bicense.ifica.com at 04/26/2023 08:16:54AM 
Table 2 Multivariate linear regression for thyroid hormones in women.

\begin{tabular}{|c|c|c|}
\hline \multicolumn{2}{|c|}{ Independent variables } & \multirow[t]{2}{*}{ FT3 } \\
\hline \multicolumn{2}{|l|}{ Model 1} & \\
\hline \multirow[t]{2}{*}{ Total } & Fat mass & $0.021(0.402)$ \\
\hline & Fat $\%$ & $0.050(0.976)$ \\
\hline \multirow[t]{2}{*}{ Trunk } & Fat mass & $0.042(0.818)$ \\
\hline & Fat $\%$ & $0.056(1.111)$ \\
\hline \multirow[t]{2}{*}{ Arm } & Fat mass & $-0.003(-0.063)$ \\
\hline & Fat $\%$ & $0.004(0.069)$ \\
\hline \multirow[t]{2}{*}{ Leg } & Fat mass & $-0.019(-0.382)$ \\
\hline & Fat $\%$ & $-0.026(-0.530)$ \\
\hline \multicolumn{2}{|c|}{ Leg fat mass to trunk fat mass ratio } & $-0.116(-2.464)^{a}$ \\
\hline \multicolumn{3}{|c|}{ Model 2} \\
\hline \multirow[t]{2}{*}{ Trunk } & Fat mass & $0.303(2.628)^{b}$ \\
\hline & fat $\%$ & $0.218(2.582)^{a}$ \\
\hline \multirow[t]{2}{*}{ Leg } & Fat mass & $-0.285(-2.525)^{a}$ \\
\hline & fat $\%$ & $-0.195(-2.388)^{a}$ \\
\hline
\end{tabular}

\begin{tabular}{c}
\hline FT4 \\
\hline $0.021(0.407)$ \\
$-0.003(-0.063)$ \\
$0.031(0.597)$ \\
$-0.005(-0.102)$ \\
$0.008(0.160)$ \\
$-0.019(-0.376)$ \\
$0.003(0.050)$ \\
$-0.048(-0.970)$ \\
$-0.032(-0.667)$ \\
\\
$0.146(1.244)$ \\
$0.097(1.130)$ \\
$-0.126(-1.092)$ \\
$-0.124(-1.486)$ \\
\hline
\end{tabular}

\begin{tabular}{c}
\hline TSH \\
\hline$-0.037(-0.693)$ \\
$-0.053(-1.019)$ \\
$-0.041(-0.783)$ \\
$-0.050(-0.968)$ \\
$-0.022(-0.428)$ \\
$-0.025(-0.489)$ \\
$-0.030(-0.572)$ \\
$-0.032(-0.634)$ \\
$0.073(1.505)$ \\
$-0.072(-0.609)$ \\
$-0.067(-0.768)$ \\
$0.034(0.291)$ \\
$0.020(0.236)$
\end{tabular}

Data were expressed as standardized $\beta$ (t). ${ }^{a} P<0.05,{ }^{b} P<0.01$.

Model 1 was adjusted for age, homeostasis model assessment-insulin resistance, diastolic blood pressure, low-density lipoprotein cholesterol and estradiol.

In model 2, all confounding factors included in model 1 were adjusted, in addition that trunk fat mass was adjusted for leg fat mass, trunk fat\% was adjusted for leg fat\%, leg fat mass was adjusted for trunk fat mass, leg fat\% was adjusted for trunk fat\%.

fat\%, fat percentage; FT3, free triiodothyronine; FT4, free thyroxine; TSH, thyroid-stimulating hormone.

Because FT3 promotes adipose decomposition and increases the basal metabolic rate (4), a high level of FT3 in the obese population was considered a compensatory effect under the condition of energy surplus according to the conventional view (6). However, in recent years, some studies found that a high level of FT3 within the reference range is related to an increased risk of $\operatorname{NAFLD}(7,8)$. In the Lifelines cohort study, the risk of NAFLD increased 1.34-fold for each 1 standard deviation increase in FT3 in the euthyroid population (7). In a euthyroid Chinese population, a high level of FT3 was an independent predictive factor of NAFLD (8). Roef et al. found that FT3 was positively related to multiple adverse metabolic and cardiovascular risk factors in a euthyroid middle-aged population (5). Although there is still a lack of evidence from prospective studies, a high level of FT3 within the reference range may be a potential adverse metabolic marker.

Trunk fat and leg fat have exhibited inverse relationships with type 2 diabetes, cardiovascular disease and multiple metabolic and cardiovascular risk factors $(3,10,11,24,25)$. There are large discrepancies between trunk fat and leg fat in the uptake and release of free fatty acids (26). Trunk fat is more sensitive to lipolysis stimulus. Leg fat has a lower lipolysis rate and is the 'storage pool' of circulating ectopic lipids. Leg fat can stabilize free fatty acids that are released by trunk fat and thus decrease lipotoxicity (21). Trunk fat and leg fat also differ in the release of adipokines and inflammatory factors
$(11,27,28)$; however, few studies have explored the relationships between adipokines and FT3. Further research is needed to clarify the mechanisms underlying the correlations between trunk fat, leg fat and FT3.

Our study has some limitations. First, the study subjects were middle-aged and elderly; thus, the results may not be generalizable to other age groups. Second, the present study did not fully consider some information such as luteinizing hormone, folliclestimulating hormone and selective estrogen receptor modulators. Third, due to the nature of the cross-sectional study, causality cannot be deduced. Further prospective studies are needed to elucidate the causal relationship between segmental fat distribution and FT3.

\section{Conclusions}

In euthyroid postmenopausal women, trunk fat is positively related to FT3, while leg fat is negatively related to FT3. Our findings supported that a high level of FT3 within the reference range was related to adverse fat distribution. Further studies are needed to clarify the causality and underlying mechanisms.

\section{Declaration of interest}

The authors declare that there is no conflict of interest that could be perceived as prejudicing the impartiality of the research reported. 


\section{Funding}

This work was supported by the National Key R\&D Program of China (2016YFA0502003).

\section{References}

1 Dale CE, Fatemifar G, Palmer TM, White J, Prieto-Merino D, Zabaneh D, Engmann JEL, Shah T, Wong A, Warren HR, et al. Causal associations of adiposity and body fat distribution with coronary heart disease, stroke subtypes, and type 2 diabetes mellitus: a Mendelian randomization analysis. Circulation 2017135 2373-2388. (https://doi.org/10.1161/CIRCULATIONAHA.116.026560)

2 Emdin CA, Khera AV, Natarajan P, Klarin D, Zekavat SM, Hsiao AJ $\&$ Kathiresan S. Genetic association of waist-to-hip ratio with cardiometabolic traits, type 2 diabetes, and coronary heart disease. JAMA 2017317 626-634. (https://doi.org/10.1001/jama.2016.21042)

3 Vasan SK, Osmond C, Canoy D, Christodoulides C, Neville MJ, Di Gravio C, Fall CHD \& Karpe F. Comparison of regional fat measurements by dual-energy X-ray absorptiometry and conventional anthropometry and their association with markers of diabetes and cardiovascular disease risk. International Journal of Obesity 201842 850-857. (https://doi.org/10.1038/ijo.2017.289)

4 Mullur R, Liu YY \& Brent GA. Thyroid hormone regulation of metabolism. Physiological Reviews 201494 355-382. (https://doi. org/10.1152/physrev.00030.2013)

5 Roef GL, Rietzschel ER, Van Daele CM, Taes YE, De Buyzere ML, Gillebert TC \& Kaufman JM. Triiodothyronine and free thyroxine levels are differentially associated with metabolic profile and adiposity-related cardiovascular risk markers in euthyroid middleaged subjects. Thyroid 201424 223-231. (https://doi.org/10.1089/ thy.2013.0314)

6 De Pergola G, Ciampolillo A, Paolotti S, Trerotoli P \& Giorgino R. Free triiodothyronine and thyroid stimulating hormone are directly associated with waist circumference, independently of insulin resistance, metabolic parameters and blood pressure in overweight and obese women. Clinical Endocrinology 200767 265-269. (https:// doi.org/10.1111/j.1365-2265.2007.02874.x)

7 van den Berg EH, van Tienhoven-Wind LJ, Amini M, Schreuder TC, Faber KN, Blokzijl H \& Dullaart RP. Higher free triiodothyronine is associated with non-alcoholic fatty liver disease in euthyroid subjects: the lifelines cohort study. Metabolism: Clinical and Experimental 201767 62-71. (https://doi.org/10.1016/j. metabol.2016.11.002)

8 Liu G, Zheng X, Guan L, Jiang Z, Lin H, Jiang Q, Zhang N, Zhang Y, Zhang X, Yu C, et al. Free triiodothyronine levels are positively associated with non-alcoholic fatty liver disease in euthyroid middleaged subjects. Endocrine Research 201540 188-193. (https://doi.org/ 10.3109/07435800.2014.987399)

9 Pietrobelli A, Rubiano F, St-Onge MP \& Heymsfield SB. New bioimpedance analysis system: improved phenotyping with whole-body analysis. European Journal of Clinical Nutrition 200458 1479-1484. (https://doi.org/10.1038/sj.ejcn.1601993)

10 Snijder MB, Dekker JM, Visser M, Bouter LM, Stehouwer CD, Yudkin JS, Heine RJ, Nijpels G, Seidell JC \& Hoorn study. Trunk fat and leg fat have independent and opposite associations with fasting and postload glucose levels: the Hoorn study. Diabetes Care 200427 372-377. (https://doi.org/10.2337/diacare.27.2.372)

11 Wu H, Qi Q, Yu Z, Sun Q, Wang J, Franco OH, Sun L, Li H, Liu Y, $\mathrm{Hu} \mathrm{FB}$, et al. Independent and opposite associations of trunk and leg fat depots with adipokines, inflammatory markers, and metabolic syndrome in middle-aged and older Chinese men and women. Journal of Clinical Endocrinology \& Metabolism 201095 4389-4398. (https://doi.org/10.1210/jc.2010-0181)
12 Sanchez-Lopez M, Ortega FB, Moya-Martinez P, Lopez-Martinez S, Ortiz-Galeano I, Gomez-Marcos MA, Sjostrom M \& MartinezVizcaino V. Leg fat might be more protective than arm fat in relation to lipid profile. European Journal of Nutrition 201352 489-495. (https://doi.org/10.1007/s00394-012-0350-4)

$13 \mathrm{Hu} \mathrm{G}$, Bouchard C, Bray GA, Greenway FL, Johnson WD, Newton RL, Jr, Ravussin E, Ryan DH \& Katzmarzyk PT. Trunk versus extremity adiposity and cardiometabolic risk factors in white and African American adults. Diabetes Care 201134 1415-1418. (https://doi. org/10.2337/dc10-2019)

14 National Collaborating Centre for Women's and Children's Health. Menopause: Full guideline. Clinical guideline: methods, evidence and recommendations. London, UK: National Institute for Health and Care Excellence (UK), 2015. (available at: https://www.nice.org.uk/ guidance/ng23/evidence/full-guideline-559549261)

15 Xu Y, Ma X, Shen Y, Gu C, Tang J \& Bao Y. Role of hyperglycaemia in the relationship between serum osteocalcin levels and relative skeletal muscle index. Clinical Nutrition 2018 [epub]. (https://doi. org/10.1016/j.clnu.2018.11.025)

16 Matthews DR, Hosker JP, Rudenski AS, Naylor BA, Treacher DF \& Turner RC. Homeostasis model assessment: insulin resistance and beta-cell function from fasting plasma glucose and insulin concentrations in man. Diabetologia 198528 412-419. (https://doi. org/10.1007/bf00280883)

17 Taylor PN, Richmond R, Davies N, Sayers A, Stevenson K, Woltersdorf W, Taylor A, Groom A, Northstone K, Ring S, et al. Paradoxical relationship between body mass index and thyroid hormone levels: a study using Mendelian randomization. Journal of Clinical Endocrinology \& Metabolism 2016101 730-738. (https://doi. org/10.1210/jc.2015-3505)

18 Lambrinoudaki I, Armeni E, Rizos D, Georgiopoulos G, Athanasouli F, Triantafyllou N, Panoulis K, Augoulea A, Creatsa M, Alexandrou A, et al. Indices of adiposity and thyroid hormones in euthyroid postmenopausal women. European Journal of Endocrinology 2015173 237-245. (https://doi.org/10.1530/EJE-15-0141)

19 Gavi S, Feiner JJ, Melendez MM, Mynarcik DC, Gelato MC \& McNurlan MA. Limb fat to trunk fat ratio in elderly persons is a strong determinant of insulin resistance and adiponectin levels. Journals of Gerontology. Series A, Biological Sciences and Medical Sciences 200762 997-1001. (https://doi.org/10.1093/ gerona/62.9.997)

20 Auro K, Joensuu A, Fischer K, Kettunen J, Salo P, Mattsson H, Niironen M, Kaprio J, Eriksson JG, Lehtimaki T, et al. A metabolic view on menopause and ageing. Nature Communications 201454708. (https://doi.org/10.1038/ncomms5708)

21 Tchkonia T, Thomou T, Zhu Y, Karagiannides I, Pothoulakis C, Jensen MD \& Kirkland JL. Mechanisms and metabolic implications of regional differences among fat depots. Cell Metabolism 201317 644-656. (https://doi.org/10.1016/j.cmet.2013.03.008)

22 Koutsari C, Ali AH, Mundi MS \& Jensen MD. Storage of circulating free fatty acid in adipose tissue of postabsorptive humans: quantitative measures and implications for body fat distribution. Diabetes 201160 2032-2040. (https://doi. org/10.2337/db11-0154)

23 Rask-Andersen M, Karlsson T, Ek WE \& Johansson A. Genome-wide association study of body fat distribution identifies adiposity loci and sex-specific genetic effects. Nature Communications 201910339. (https://doi.org/10.1038/s41467-018-08000-4)

24 Yano Y, Vongpatanasin W, Ayers C, Turer A, Chandra A, Carnethon MR, Greenland P, de Lemos JA \& Neeland IJ. Regional fat distribution and blood pressure level and variability: the Dallas Heart study. Hypertension 201668 576-583. (https://doi.org/10.1161/ HYPERTENSIONAHA.116.07876)

25 Lee M, Choh AC, Demerath EW, Towne B, Siervogel RM \& Czerwinski SA. Associations between trunk, leg and total body https://ec.bioscientifica.com https://doi.org/10.1530/EC-19-0394 (c) 2019 The authors Published by Bioscientifica Ltd
This work is licensed under a Creative Commons Attribution-NonCommercial-NoDerivatives 4.0 Internationab ticense.ifica.com at 04/26/2023 08:16:54AM 
adiposity with arterial stiffness. American Journal of Hypertension 2012 25 1131-1137. (https://doi.org/10.1038/ajh.2012.92)

26 Ebbert JO \& Jensen MD. Fat depots, free fatty acids, and dyslipidemia Nutrients 20135 498-508. (https://doi.org/10.3390/nu5020498)

27 Pinnick KE, Neville MJ, Fielding BA, Frayn KN, Karpe F \& Hodson L. Gluteofemoral adipose tissue plays a major role in production of the lipokine palmitoleate in humans. Diabetes 201261 1399-1403. (https://doi.org/10.2337/db11-1810)

28 Antony B, Jones G, Stannus O, Blizzard L \& Ding C. Body fat predicts an increase and limb muscle strength predicts a decrease in leptin in older adults over 2.6 years. Clinical Endocrinology 201379 652-660. (https://doi.org/10.1111/cen.12101)

Received in final form 16 September 2019

Accepted 26 September 2019

Accepted Preprint published online 26 September 2019 (c) 2019 The authors Published by Bioscientifica Ltd 